\title{
Risky Riding Behaviour Among Malaysian Young Motorcyclists
}

\author{
Muhammad Safizal Abdullah', Muhammad Asyraf Mohamed Kassim ${ }^{1}$, and M. F. Mansor ${ }^{1}$ \\ ${ }^{1}$ School of Business Innovation and Technopreneurship, (UniMAP)
}

\begin{abstract}
The main objective of this study was to explore the relationship between riding attitude, sensation seeking, anger and riding confidence with risky riding behaviour among motorcyclist at University Malaysia Perlis (UniMAP). Partial Least Squares of Structural equation modelling (SEM) and Statistical Package Social Science (SPSS) are utilized to determine the direct effect of the variables. The results discovered that riding attitude, sensation seeking, and anger had shown positive significant relationship towards risky riding behaviour while riding confidence has shown negative significant relationship towards risky riding behaviour.
\end{abstract}

Keywords: Riding Attitude, Sensation Seeking, Anger, Riding Confidence, Risky Driving Behaviour

\section{Introduction}

Road accident seems to be a never-ending issue in Malaysia. Statistics shows that road accidents record an increase each year as shown in Figure 1.

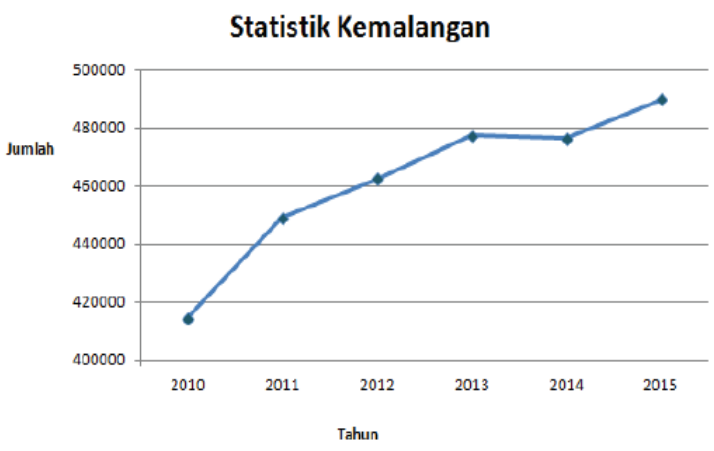

Figure 1. Road Accidents in Malaysia 2010 - 2015

Statistics provided by the Department of Road Transport has shown an increase in the number of accidents from year 2010-2015. In 2015, the number of accidents were 490,000 cases in which it has been an increase about $13.41 \%$ compared to year 2014 , and the number of also increased from 6706 to 6674 in the respective time periods.

Motorcyclists are more prone to accident when they are on the road compared to drivers of other vehicles. According to the Road Safety Department of Malaysia, of the 131 deaths from road accidents, 85 cases involving motorcycles in 2015 from January to July. While, according to Royal Malaysia Police (RMP) report, among 6,706 deaths in 2015, 3,816 were motorcyclists and 387 were with the passengers. Individuals aged between 16 to 20 years old had the highest number of deaths in motorcycle road accident which amounted to 934 cases, followed by the age between 21 to 25 years ( 828 cases), 26 to 30 years (641), 31 to 35 years (579), and the remaining 36 years above. Therefore, this study will examine the risky riding behaviour among the young motorcyclists, and factors influencing risky riding behaviour will be investigated.

\section{Underpinning Theory}

Theory of Planned Behaviour (TPB) is widely used in various studies regarding human behaviour. According to $\mathrm{TPB}$, there are three main predictors affecting individual intention towards behaviour, namely attitude toward the behaviour, subjective norm, and perceived behavioural control (Ajzen, 2005). Ajzen (1991) argued that individual's intention was a determinant of their behaviour. Intentions were cause by attitude, subjective norms, and perceived behaviouralcontrol. Therefore, this study utilised TPB theory. According to Ajzen (1991), TPB helps to understand how we change the behaviour of people. The TPB is a theory, which predicts deliberate behaviour, because behaviour can be deliberative and planned. Therefore, the theory TPB is a reference that can be used as an underpinning theory in this study.

\section{Methodology}

In this study, four predictors will be examined in relation to risky riding behaviour such as riding attitude, sensation seeking, anger, and riding confidence as the theoretical framework in figure 2. 


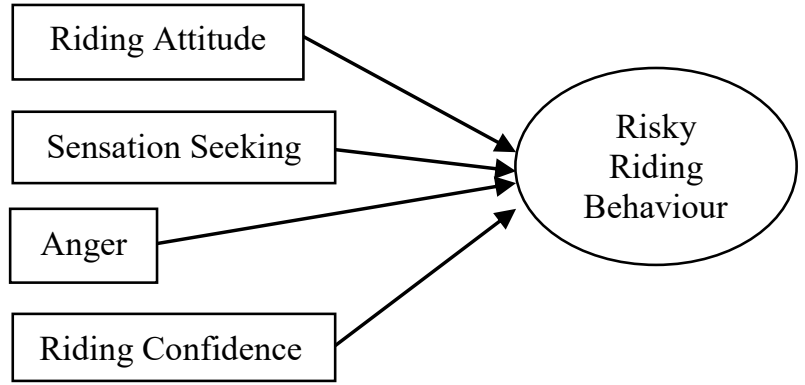

Figure 2. Risky Riding Behaviour Theoretical Framework

This framework shows the main factors that will have significant effect on risky riding behaviour. Therefore, the hypotheses of the study will be:

H1: Riding attitudes has positive significant effect on risky riding behaviour

$\mathrm{H} 2$ : Sensation seeking has positive significant effect on risky riding behaviour

H3: Anger has positive significant effect on risky riding behaviour

H4: Riding confidence has negative significant effect on risky riding behaviour

Self-administered questionnaires were developed and distributed to young undergraduate students in UniMAP. Respondents were students aged $19-21$ years old. The questionnaires were distributed using a simple random sampling method. In total, 600 questionnaires containing riding attitude, sensation seeking, anger and riding confidence scales and risky riding behaviour assessment were distributed by hand to the respective students. The scales were measured using a five-point Likert scale ranging from (1) "strongly disagree" to (5) "strongly agree". 285 questionnaires were returned and the overall response was 47.5 per cent. PLS-SEM were used to assess the goodness of measures and to test the hypotheses for this study.

\section{Findings}

\subsection{Respondent's Profile}

Descriptive statistics of the final sample are shown in Table 1. These variables are considered as control variables in the following analysis.

Table 1. Profile of respondents

\begin{tabular}{|c|c|c|}
\hline \multirow{2}{*}{ Profile } & Description & Frequency \\
\hline \multirow{2}{*}{ Gender } & Female & 110 \\
\cline { 2 - 3 } & Male & 175 \\
\hline \multirow{2}{*}{ Marital Status } & Single & 280 \\
\cline { 2 - 3 } & Married & 5 \\
\hline \multirow{4}{*}{ Ethnic Group } & Malay & 134 \\
\cline { 2 - 3 } & Chinese & 107 \\
\cline { 2 - 3 } & Indian & 40 \\
\cline { 2 - 3 } & Other & 4 \\
\hline
\end{tabular}

\begin{tabular}{|c|c|c|}
\hline \multirow{3}{*}{$\begin{array}{c}\text { Types of } \\
\text { Licenses }\end{array}$} & B2 & 140 \\
\cline { 2 - 3 } & D & 55 \\
\cline { 2 - 3 } & B2 \& D & 72 \\
\hline \multirow{2}{*}{$\begin{array}{c}\text { Preferred } \\
\text { Vehicle }\end{array}$} & None & 18 \\
\hline \multirow{5}{*}{$\begin{array}{c}\text { Dotorcycle } \\
\text { Expering }\end{array}$} & Motorcar & 200 \\
\hline & $\begin{array}{c}\text { Below 5 } \\
\text { Month }\end{array}$ & 55 \\
\cline { 2 - 3 } & $\begin{array}{c}\text { Month - } \\
\text { Year }\end{array}$ & 103 \\
\cline { 2 - 3 } & $\begin{array}{c}\text { 1 Year - 5 } \\
\text { Year }\end{array}$ & 98 \\
\cline { 2 - 3 } & $\begin{array}{c}\text { 5 Years } \\
\text { Above }\end{array}$ \\
\hline
\end{tabular}

\subsection{Goodness of Measures}

The goodness of measures for the variables in the study was assessed using construct validity, convergent validity, discriminant validity, and reliability analysis. For the purpose of construct validity, Hair et al. (2013) indicated that every loading that are greater than 0.50 on a particular construct are considered significant. Therefore, loadings below 0.50 were removed and there were no reported cross loadings. As a result, the constructs were valid for this study. Table 2 shows the factor loadings for each construct.

Table 2. Results of measurement model

\begin{tabular}{|c|c|c|c|c|}
\hline $\begin{array}{c}\text { Model } \\
\text { Construct }\end{array}$ & Items & Loadings & AVE & CR \\
\hline Riding & RA1 & 0.778 & \multirow[t]{8}{*}{0.761} & \multirow[t]{8}{*}{0.863} \\
\hline \multirow{7}{*}{ Attitudes } & RA2 & 0.739 & & \\
\hline & RA3 & 0.762 & & \\
\hline & RA4 & 0.766 & & \\
\hline & RA5 & 0.779 & & \\
\hline & RA7 & 0.720 & & \\
\hline & RA8 & 0.668 & & \\
\hline & RA9 & 0.709 & & \\
\hline \multirow{8}{*}{$\begin{array}{c}\text { Sensation } \\
\text { Seeking }\end{array}$} & SS1 & 0.858 & \multirow[t]{8}{*}{0.749} & \multirow[t]{8}{*}{0.907} \\
\hline & SS2 & 0.830 & & \\
\hline & SS3 & 0.832 & & \\
\hline & SS4 & 0.820 & & \\
\hline & SS5 & 0.812 & & \\
\hline & SS6 & 0.771 & & \\
\hline & SS7 & 0.795 & & \\
\hline & SS8 & 0.887 & & \\
\hline \multirow[t]{5}{*}{ Anger } & A1 & 0.826 & \multirow[t]{5}{*}{0.756} & \multirow[t]{5}{*}{0.929} \\
\hline & A2 & 0.682 & & \\
\hline & A3 & 0.816 & & \\
\hline & A4 & 0.593 & & \\
\hline & A5 & 0.801 & & \\
\hline Riding & $\mathrm{RC} 1$ & 0.742 & \multirow[t]{7}{*}{0.746} & \multirow[t]{7}{*}{0.914} \\
\hline \multirow{6}{*}{ Confidence } & $\mathrm{RC} 2$ & 0.869 & & \\
\hline & $\mathrm{RC} 3$ & 0.722 & & \\
\hline & $\mathrm{RC} 4$ & 0.869 & & \\
\hline & RC5 & 0.824 & & \\
\hline & RC6 & 0.845 & & \\
\hline & $\mathrm{RC7}$ & 0.783 & & \\
\hline Risky & RB1 & 0.784 & 0.883 & 0.945 \\
\hline Riding & RB2 & 0.676 & & \\
\hline Behaviour & RB3 & 0.748 & & \\
\hline
\end{tabular}




\begin{tabular}{|l|l|l|l|l|}
\hline & RB4 & 0.814 & & \\
& RB6 & 0.660 & & \\
& RB7 & 0.709 & & \\
& RB8 & 0.594 & & \\
& RB9 & 0.839 & & \\
RB10 & 0.788 & & \\
\hline
\end{tabular}

Then, the correlations between the measures are compared with the square root of the AVEs in order to assess the discriminant validity. Table 5 exhibits all of the correlations between the measures were smaller than the square root of thee shown on the diagonals. Therefore, the items measuring the constructs discriminant validity for this study are satisfactory. Finally, reliability was also accessed via Cronbach's alpha coefficient, which should have a value higher than the recommended value of 0.60 as indicated by Nunally and Berstein (1994). In addition, all of the constructs have alpha values of above the recommended value and therefore, the measures are reliable.

Table 3. Results of discriminant validity

\begin{tabular}{|l|l|l|l|l|l|}
\hline & A & RA & RC & RB & SS \\
\hline A & $\mathbf{0 . 8}$ & & & & \\
\hline RA & 0.5 & $\mathbf{0 . 7}$ & & & \\
\hline RC & 0.6 & 0.6 & $\mathbf{0 . 7}$ & & \\
\hline RB & 0.5 & 0.6 & 0.5 & $\mathbf{0 . 8}$ & \\
\hline SS & 0.6 & 0.6 & 0.5 & 0.7 & $\mathbf{0 . 9}$ \\
\hline
\end{tabular}

Note: The bolded diagonals represent square root of the $A V E$ while the off-diagonals represent the correlation.

\subsection{Structural Model}

The purpose of structural model is to determine the relationship between variables that were hypothesized in the framework. Hair et al., (2013) indicated that the structural model is a set of one or more dependence relationships linking the hypothesized model's constructs, such as the structural theory, which refers to the conceptual representation of the relationships between constructs. In addition, the structural model is more helpful in representing the interrelationships between constructs (Hair et al., 2013). On top of that, because of the main objective of PLS is to predict the structural model was assessed in terms of the coefficient of the variance explained (R2) and the significance of path coefficients. (Hair et al., 2013).

\subsubsection{Direct Effects}

As shown in Figure 3, risky riding behaviour had an R2 value of 0.817 , which was on the high level of variance explained and also indicated that $81.7 \%$ of the variance in risky riding behaviour could be explained by the dimensions of riding attitude, sensation seeking, anger and riding confidence. The results from bootstrapping showed that riding attitude $(\beta=0.41, \mathrm{t}=6.00, \mathrm{p}<0.01$ ( 1 tailed), sensation making ( $\beta=0.513, t=10.015, p<$ 0.01 ( 1 tailed), anger $(\beta=0.823, t=2.112, p<0.01$ (1 tailed), and riding confidence $(\beta=-0.061, t=1.280, p$
$<0.01$ (1 tailed) had positive significant effects on risky riding behaviour.

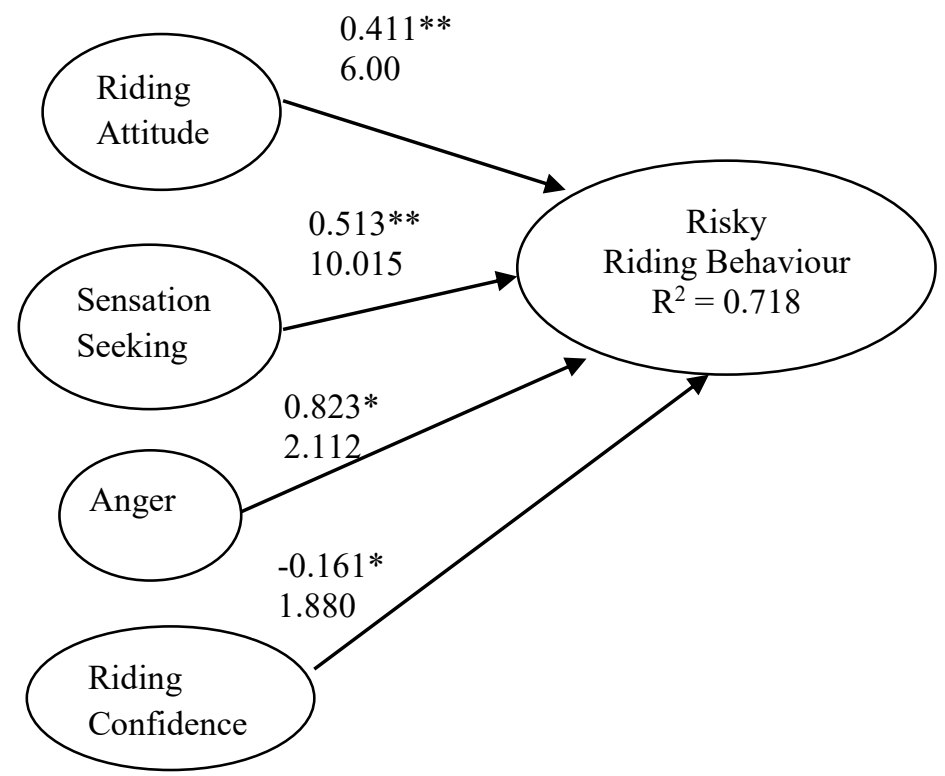

Figure 3. Results of structural model direct effects between riding attitude, sensation seeking, anger and riding confidence and risky riding behaviour.

Note. Value within parenthesis is $t$-value. ${ }^{* *} p<0.01(t>$ 2.326), ${ }^{*} p<0.05(t>1.645)$ (based on one tailed test).

\section{Discussion}

After assessing the validity and reliability of the measurement model, structural model is then examined to test the hypothesis of the study.

The first hypothesis (H1) assume that the attitudes of riding is significantly affects the risky riding behaviour. Results found that the assumptions are correct where (riding attitude) has a significant positive correlation with risky riding behaviour. In conclusion, H1 is supported or accepted.

The second hypothesis (H2) concluded that sensation seeking is significantly affects the risky riding behaviour. The results obtained showed that sensation seeking and risky riding behaviour has a significant positive relationship. Thus, H2 also was supported and accepted hypothesis.

The third hypothesis (H3) also assume that anger is significantly affects the risky riding behaviour. Results revealed that anger has a significant positive correlation with risky riding behaviour and the results have been made $\mathrm{H} 3$ also supported and accepted in the study.

Finally (H4) stated that confidence riding is significantly affects the risky riding behaviour. The results of these experiments, it has been shown that riding confidence provide results significantly negative correlation with risky riding behaviour. Thus, H4 is also a hypothesis that is accepted and supported. The summary of hypotheses is shown in 4 . 
Table 4. Summary of hypotheses

\begin{tabular}{|l|l|}
\hline Hypotheses Statement & Results \\
\hline H1: Riding Attitude has & \\
significance positive & \multirow{2}{*}{ Accepted } \\
relationship with RB. & \\
\cline { 1 - 2 } H2: Sensation Seeking has & \\
significance positive & \\
relationship with RB. & \\
\cline { 1 - 2 } H3: Anger has significance & \\
positive relationship with RB. & \\
\cline { 1 - 1 } H4: Riding Confidence has & \\
significance negative & \\
relationship with RB. & \\
\hline
\end{tabular}

\subsection{Riding Attitude, Sensation Seeking, Anger, Riding Confidence and Risky Riding Behaviour}

The present study revealed that riding attitude, sensation seeking, anger and riding confidence have a positive significant relationship with risky riding behaviour.

This result can be supported by previous study on riding attitude such as by Jinn-Tsai Wong, Yi-Shih Chung, and Shih-Hsuan Huang (2009) and Deborah, Barry, Katherine, Melissa, Cynthid, and Darren (2011). This means that the riding attitude can lead to a safety risk to motorists. An attitude such as ignoring traffic rules must be ignored to escape from heavy traffic is one of the risky driving behaviour. Most young drivers age 17-21 were discovered to be more prone to ignore the traffic rules in order to escape from heavy traffic.

Next, the significance of sensation seeking and risky driving behaviour has been supported by previous studies such as Ching-Fu Chen (2009). Sensation seeking has been discovered to be one of the crucial factors of risky riding behaviour.

On the other hand, the findings of significance relationship of anger and risky riding behaviour is proven valid as motorcyclist will trigger a tremendous attitude like bringing speed, vehicle interjected, and trying to keep up with other vehicles when they feel angry because being honk by other vehicles as it will lead to the risk of other riders or other road users.

Lastly, findings revealed that riding confidence has negative significance relationship with risky driving behaviour as more experienced driver will have more confidence to drive a vehicle and this will reduce the risk to own and other on the road.

\section{Conclusion}

Study on risky riding behaviour is not a new investigation. This is because other countries are also facing the same problem on the issue of accidents is increasing in their respective countries. With this type of research, one of the goals of this study is to provide a deeper awareness to motorcyclists will attitudes that tend to risky riding behaviour, especially to motorcyclists in UniMAP, Perlis, Malaysia. To achieve this, the current study was to propose and validate a model consisting of four independent variables, riding attitude, sensation seeking, anger and confidence riding. The proposed model successfully provide significant results such as riding attitude, sensation seeking and anger found to be significantly positive with risky riding behaviour, while riding confidence has a negative significant with risky riding behaviour.

Last but not least, the issue of accidents involving attitudes rider or driver has received less attention in research to date. Therefore, the study of this must be improved in order to help bring awareness to the community about the importance of personal safety on the road.

\section{References}

Ajzen, I., 1988. Attitudes, Personality and Behaviour. Open Press University, Buckingham.

Malaysia, J. K. J. R. (2015). Indeks Kematian Jalan Raya 2004-2014: Jabatan Keselamatan Jalan Raya Malaysia.

Malaysia, J. K. J. R. (2015). Indeks Kematian Jalan Raya 2004-2014: Jabatan Keselamatan Jalan Raya Malaysia

Sadali, I. (2016). PDRM rekod 6,706 kematian akibat kemalangan jalan raya pada tahun lalu - purata 18 maut sehari [Electronic Version].

Langen, A. D. (2009). CHAPTER 3 Research Design and Methodology. Example 3 Reseacrh Design and Methodology.

Chen, C.-F. (2009). Personality, safety attitudes and risky driving behaviors-Evidence from young Taiwanese motorcyclists. Accident Analysis and Prevention.

Deborah J. Tunnicliff a, B. C. W., Katherine M. Whiteb, Melissa K. Hydeb,, \& Cynthia C. Schonfelda, D. E. W. (2011). Understanding the factors influencing safe and unsafe motorcycle rider intentions. Accident Analysis and Prevention.

Jinn-Tsai Wong, Y.-S. C., Shih-Hsuan Huang. (2009). Determinants behind young motorcyclists' risky riding behavior. Accident Analysis and Prevention.

Mehri Ali, M. M. S. S., Morowatisharifabad Mohammad Ali,„\&Haidar, N. (2010). Determinants of helmet use behaviour among employed motorcycle riders in Yazd, Iran based on theory of planned behaviour. Injury.

Nur Sabahiah Abdul Sukor, A. K. M. T., Satoshi Fujii. (2016). Analysis of correlations between psychological factors and self-reported behavior of motorcyclists in Malaysia, depending on self-reported usage of different types of motorcycle facility. Transportation Research Part F.

TürkerÖzkan, T. L., BurakDo gruyol, ZümrütYıldırım, Ahmet Coymak. (2011). Motorcycle accidents, rider behaviour, and psychological models. Accident Analysis and Prevention.

Wong, Y.-S. C. a. J.-T. (2011). Beyond general behavioral theories: Structural discrepancy in young 
motorcyclist's risky driving behavior and its policy implications. Accident Analysis and Prevention. 